\title{
Effectiveness of genetic selection for prolificacy in pigs
}

\author{
M. Bichard* and P. J. David $\dagger$ \\ *Pig Improvement Company, Fyfield Wick, Abingdon, Oxfordshire OXI3 SNA, U.K. and \\ †Box 348, Franklin, Kentucky 42134, U.S.A.
}

Summary. This paper attempts to summarize and discuss the new evidence on the effectiveness of selection for prolificacy. In recent years selection between lines, and the adoption of formal cross-breeding programmes, have led to considerable improvements at a commercial level. Within-line selection has not been tackled seriously except in a few experiments. The mainly negative results from these should not lead to the conclusion that progress is impossible, but rather that it needs larger resources, applied consistently for several generations, to overcome the inherent problems.

There are now many estimates of genetic parameters, based on large data sets, and these have helped to clear up some of the confusion resulting from previous inadequate material. A heritability of around 0.1 , repeatability of 0.15 , and fairly high genetic correlations between successive records seem justified. The negative environmental effect of being reared in a large litter is frequently present, but there is no good reason why this should seriously affect attempts to improve the trait by selection.

Information from a candidate's relatives other than its dam can undoubtedly increase the accuracy with which its breeding value is estimated, but the routine use of such data in practical programmes is not straightforward.

Prolificacy is only one group of traits contributing to net economic worth. The need to strike a balance between all relevant traits is explored in the particular context of a scheme based on hyperprolific sows. Finally, selection can only have lasting and cumulative effectiveness if it is applied at the top of a pyramid of improvement. Both culling and selection of replacement gilts within the commercial sector are largely irrelevant.

\section{Introduction}

The starting point of this paper is the review by Hill \& Webb (1982), and detailed consideration is not given to the literature which it covered. Avoiding the topics covered by Johnson, Zimmerman, Lamberson \& Sasaki (1985) and Legault (1985), this paper gives a short initial account of the theory of genetic selection and a review of new evidence from selection experiments. More detailed attention will then be given to some specific topics on which new work has appeared. These include the relevance of maternal environmental effects, correlations between successive sow records, and the use of information from relatives when estimating a candidate's breeding value. The theory of maximizing overall benefit in a selection programme which exploits the hyperprolific female is outlined. Finally, selection for prolificacy is placed in the overall context of the dynamics of genetic change in a pig industry.

\section{Basic principles}

Genetic change is made in three different ways:

(a) selection between breeds or lines;

(b) selection among different crossbreeding systems;

(c) selection within chosen breeds or lines. 
The first exploits gene frequency differences between lines created by previous breeders. The second involves the harnessing of the effects of heterosis when unrelated lines are crossed. Both methods are simple, but achieve their maximum potential within a very few generations. Only within-line selection, which exploits genetic differences between individuals, can continue to yield progress for many generations. This occurs as new variation is constantly exposed and the frequency of the more favourable genotypes is steadily increased. Since there are usually also non-genetic (or environmental) factors acting on individuals, these effects become confused with the genetic differences. Hence within-line selection is nearly always an inaccurate process, and the resultant rate of change is rather slow, typically $1-3 \%$ of the mean per year (Smith, 1984). Nevertheless it is both dependable and cumulative.

\section{Between-line selection}

Between-breed or -line selection has been the most effective way of raising sow productivity to date. As a technique it has two advantages. First, the superiority of an alternative line can be evaluated so accurately, by measuring many representatives of the line, that the difference is effectively $100 \%$ 'heritable'. Second, the improvement can be realized just as rapidly as the new line can be brought in and expanded. The widespread displacement of other breeds in Europe since 1950 by Large White and Landrace types has undoubtedly contributed greatly to the impressive and steady improvements in pigs weaned per sow per year. But the disadvantages of genetic change by line substitution are that overall profitability depends upon a whole range of traits, including efficiency of feed use and carcass quality, and so a new prolific line could easily depress performance in these other traits. It is for this reason that exploitation of the breeds from the region of Lake Taihu in central-eastern China will be a more difficult task in western countries, since their extreme prolificacy (Cheng, 1983) is accompanied by slow growth and fat carcasses.

\section{Cross-breeding}

Improvement through cross-breeding is also a rapid technique, and again efficient systems have become widespread in many countries in the past 15 years. $F_{1}$ or three-line-cross sows between prolific breeds make the most productive commercial animals, and are increasingly used worldwide. Constraints on their more rapid adoption come from the organizational problems of having a steady supply of healthy and economically priced gilts available when needed on the farm. These problems can be solved either through specialist suppliers of replacement parent gilts or, if the production unit is large enough, through a carefully controlled grandparent unit within the commercial herd.

\section{Within-line selection}

In future, within-line selection must receive more attention since the alternative and faster ways of achieving genetic change in prolificacy already have been largely exploited.

The actual rate of genetic change is controlled by four different parameters, reproductive rate, generation interval, variation and accuracy of selection, and the breeder only has limited ability to manipulate these to his advantage.

(a) The reproductive rate of the species is fundamental: the greater the number of offspring per unit time then the smaller the proportion which must be selected to maintain the breeding herd and the better these selected individuals can be by comparison with the population mean. The breeder can take care to rear large litters from each sow and to maintain a wide boar to sow ratio, but only if his herd is large enough to avoid inbreeding.

(b) The interval between generations has a minimum of about 1 year in most types of pig, while the optimum depends upon the reproductive rate. With 3 or 4 offspring of each sex tested per litter, 
the optimum is around 1.25 years, achieved by allowing most females to have 2 litters and boars to work for 6 months before being culled.

(c) The coefficient of variation in the measured traits is largely outside the breeder's control, but, since selection involves trying to identify superior individuals, the more variation the better, providing it is not all of environmental origin.

(d) In the case of selection on the candidate's own performance, this accuracy is measured by the square root of the heritability of the trait, and again this is mainly a characteristic of that particular trait, population and environment.

The well-known formula for predicting annual genetic gain $(\Delta G)$ from within-line selection

$$
\Delta G=i h \sigma_{p} \rho / t
$$

suggests that surprisingly high rates should be possible, in spite of a low heritability, because of the high variability displayed amongst sows. A very simple system would select young boars and gilts out of their dam's first litter, based upon an estimate of her breeding value which uses information from both her first and second litter size. With boars selected from amongst the top $10 \%$ of dams $\left(i_{\mathrm{m}}=1 \cdot 76\right)$, gilts from amongst the top $33 \%$ of dams $\left(i_{f}=1 \cdot 10\right)$ the average selection intensity $i=1.43$. Assume a heritability $\left(h^{2}\right)$ of $0 \cdot 1$, a standard deviation $\left(\sigma_{\mathrm{p}}\right)$ of $2 \cdot 8$ and a generation interval $(t)$ of 1 year. The accuracy of selection $(\rho)$ of candidates based upon $n$ records on their dam is

$$
\frac{1}{2} h \sqrt{\frac{n}{1+(n-1) r}}
$$

where $r$ is the repeatability or average correlation between repeat records and assumed equal to 0.15 . For $n=2$ then $\rho=0.21$ (compared with 0.16 for one record on the dam, or 0.32 for one record on the candidate). Hence the predicted annual improvement, $\Delta G$, is 0.26 pigs/litter, or about $2 \frac{1}{2} \%$ of the mean.

\section{Evidence from selection experiments}

Little new work has been reported since Hill \& Webb's (1982) review to reconcile these optimistic predictions with the prevailing view amongst many geneticists that selection for increased litter size will be difficult. Vangen's (1981) results failed to show any phenotypic change after $5-6$ generations, although genetic trends were not estimated as no control line was maintained. No analysis of possible reasons has been published, although his results show that the population sizes were small, only 15-30 females per line.

Reasons for a complete lack of response in the 11-generation French experiment have been explored by Ollivier \& Bolet (1981), Bolet \& Legault (1982) and Ollivier (1982). The main points appear to be that both the realized selection differentials and the genetic parameters were considerably smaller than planned. The selection line should have involved 10 boars and 120 gilts per generation but infertility (failure to reach puberty or to conceive within the allotted time) meant that only an average of 53 gilts farrowed per generation (19 instead of 50 in the control line). Heritability of first, second, and the mean of first and second litter size was estimated throughout the experiment (by daughter-dam regression) to have been $0.09 \pm 0.10,0.05 \pm 0.12$ and $0.02 \pm 0.15$, instead of $0.10,0.10$ and 0.17 as planned. Although the precision of these estimates limits their interpretation, the authors raise the question of whether successive observations of litter size on the same female can validly be assumed to be repeated measurements on the same trait (with a perfect genetic correlation of +1.0 ). This is further discussed below. Finally, to contain inbreeding in the small line, selection was carried out within sire-families, hence reducing the usable genetic variation by $25 \%$.

Rutledge (1980) reported on the first two generations of selection for litter size in two small 
selection lines and a control. Results in subsequent generations of this experiment (J. J. Rutledge, unpublished observations) have not provided evidence of significant responses.

In a long-term study in Nebraska (Johnson, Zimmerman \& Kittok, 1984), the correlated response in litter size to 10 generations of effective selection for ovulation rate, expressed as a deviation from control line performance, was $0.06 \pm 0.07$ per generation, which was not significantly different from zero. In spite of this, evidence from sublines derived from the selected tine in 4 subsequent generations suggests a slightly larger total effect on litter size (a difference of $0.78 \pm 0.22$ pigs per litter). This result is not easy to interpret.

Two papers from Oklahoma (Young, Omtvedt, Whatley \& Johnson, 1983a, b) reported 6 cycles of reciprocal recurrent selection with two lines and a control between 1960 and 1970 . Selection was for 21 -day litter weight, the product of litter size and average weight at 21 days. Again the estimate of genetic trend (measured in litters from crossbred females) was non-significant $(1.04 \pm 1.25 \mathrm{~kg} /$ litter/cycle of three seasons or 1.5 years). The experiment provided no strong evidence that prolificacy will, or will not, respond to selection, in part because litter size was not the primary selection objective, in part because it was not sufficiently large either to create or to detect significant genetic changes.

Some interesting results from 10 years of selection within a closed line of Large White origin, in the Netherlands were obtained by B. A. J. Molenaar and H. A. M. van der Steen (unpublished data). The line was designated a specialized dam line within a cross-breeding system, and selected for daily tean meat gain and piglets born per sow per year. An empirical index gave little weight to litter size but most to the intervals from 220 days of age to first oestrus in gilts, and from weaning to oestrus in sows. While no estimates of genetic change were given, there were consistent phenotypic improvements in average interval from weaning to oestrus, down to about 7 days, with heritability estimated in the range $10-20 \%$, and repeatability slightly higher.

Finally, there have been several attempts to increase litter size by screening large populations and achieving a high selection differential for repeated performance. The method was first proposed by Legault \& Gruand (1976) who called the extreme individuals 'hyperprolific'. Some of the recent results from France (Legault, 1983), Norway (Vangen, 1981), England (M. Bichard, unpublished) and Australia (Tomes \& Nieisen, 1984) appear to give cause for optimism that the technique will produce real improvement. While these experiments are considered in more detail by Legault (1985), some theoretical aspects are treated in more detail later.

The conclusion must be that, while there is no reason to believe that litter size should not respond to selection like any other trait, clear evidence is still scanty. The most likely explanation for the lack of such evidence for within-line improvement is that adequate controlled experiments, of sufficient size and duration, have not yet been reported.

\section{Parameter estimates}

Hill \& Webb (1982) summarized results from several large data sets in which heritability of litter size and other traits had been estimated by different methods. They concluded that, while there was marked variation between sets, much of it probably reflected sampling error and bias from uncorrected environmental effects. They suggested that a typical figure for litter size would be about $10 \%$. Since that time several more large studies have been completed, without seriousiy challenging this conclusion (Table 1). All of these have come from Europe and have mainly involved Large White and Landrace sows. There have been some suggestions that the situation might be different in United States breeds, but two recent small analyses (Irvin \& Swiger, 1984; Bereskin, 1984) have not produced any consistent evidence; these estimates of heritability of litter size were $0.26 \pm 0.12$ and $0.04 \pm 0.02$, respectively.

A particularly useful data set from two breeds (Large White and British Landrace), within a single farm, provided over 11000 litters in a 10-year period (E. Avalos, unpublished observations). 
Table 1. Estimates of heritability of litter size (number born alive at first parity) from half-sib analyses in large data sets

\begin{tabular}{lc}
\hline Source & $h^{2} \pm$ s.e. \\
\hline G. Bolet \& C. Felgines, unpublished data* & $0.09 \pm 0.03$ \\
R. Christenson, unpublished observations cited by & \\
Johansson (1981) † & $0.13 \pm 0.02$ \\
Johansson \& Kennedy (1982), alteration by K. Johansson, & $0.11 \pm 0.02$ \\
$\quad$ unpublished observations & $0.07 \pm 0.03$ \\
Vidovic (1982) & $0.05 \pm 0.03$ \\
H. Brandt \& P. Glodek, unpublished data & $0.13 \pm 0.08$ \\
A. Löbke, H. Willeke \& F. Pirchner, unpublished data & \\
\hline
\end{tabular}

* By daughter-dam regression.

$\uparrow$ All paritics.

† Total number born.

Table 2. Several estimates of heritability $\left(h^{2} \pm\right.$ s.e. $)$ on the same data set (from E. Avalos, unpublished observations)

\begin{tabular}{ll}
\hline Daughter on dam regression, birth litter* & $0.12 \pm 0.02$ \\
Daughter on dam regression, not birth litter & $0.10 \pm 0.01$ \\
Granddaughter on grand-dam regression & $0.10 \pm 0.03$ \\
Paternal half-sib analysis & $0.08 \pm 0.06$ \\
Full-sib analysis & $0.09 \pm 0.05$ \\
\hline
\end{tabular}

- Birth litter implies that dam performance utilized in calculation of regression coefficient was the litter in which the daughter was born.

Table 3. Estimates of genetic correlation amongst repeated litter size records on same sow (from E. Avalos, unpublished observations)

\begin{tabular}{lcccccc}
\hline & \multicolumn{7}{c}{ Source of estimates* } \\
\cline { 2 - 7 } Parities & a & b & c & & d & c \\
\hline 1 and 2 & 0.47 & 2.60 & 0.72 & 1.03 & 1.06 & 1.04 \\
1 and 3 & 0.80 & 1.30 & 0.48 & 1.01 & 1.03 & 0.50 \\
1 and 4 & - & - & 0.06 & 0.99 & 1.00 & 0.46 \\
2 and 3 & 1.21 & 0.83 & 2.38 & 0.90 & 0.97 & 1.29 \\
2 and 4 & - & - & 0.58 & 0.84 & 0.97 & 1.15 \\
3 and 4 & 0 & 0 & 1.99 & 0.70 & 0.91 & 1.06 \\
\hline
\end{tabular}

*a, Johansson \& Kennedy (1982); b, A. Lobke, H. Willeke \& F. Pirchner. unpublished data; c, G. Bolet \& C. Felgines, unpublished data; d, Vidovic (1982); e, E. Avalos, unpublished data.

It enabled several different analyses to be carried out on the same data, so that heritability was estimated with reasonably small standard errors by regression of daughter on dam (inciuding or excluding the litter in which the daughter was born), regression of granddaughter on grand dam, half-sib and full-sib correlation (Table 2). It was concluded that a value of 0.1 can be used with some confidence for these breeds.

When repeated records are obtained from the same sow, even though the phenotypic correlation between these is around 0.15 , it has usually been assumed that the underlying genetic correlations were $+1 \cdot 0$. This is the basis of the predictions that the heritability of the mean of 2,3 and 4 records should be $0 \cdot 17,0.23$ and 0.28 (and hence the correlation $\rho$ between the sow's breeding 
value and her lifetime performance is $0.42,0.48$ and 0.53 ). Ollivier \& Bolet (1981) used the mean of records 1 and 2 to select the dams of replacement gilts, and the failure of their selected line to respond as predicted caused them to query the assumed genetic correlation. A summary of estimates of this correlation from this experiment and others is given in Table 3. They show considerable variation, but in general support the thesis that consecutive records have a genetic correlation close to unity although this is reduced between records more separated by time.

Tartar \& Bolet (1984) have pointed out that, if these correlations are not unity, then simply selecting on the average of successive records would not be the most appropriate method. The situation should be seen as one in which there are several different selection objectives (performance at successive parities), each with a different economic value because a normal herd contains fewer animals of the older parities. Each record on an animal tells something different about its breeding value for litter size at that and at each other parity. This is the classic selection index situation. Bolet, Tartar, Laloe \& Felgines (1984) explored two aspects of this problem. First, they showed that the normal averaging procedure produces an 'index' that is only slightly less accurate and hence less efficient than an optimum selection index, as judged by their correlations with the breeding objective. Consequently, progress will not be slowed down as a result of using the normal simpler procedure. However, predictions of possible progress may be greatly overestimated if genetic correlations between successive records fall below unity. For example, if the records were uncorrelated then the expected progress could be as low as one quarter of that normally assumed, whichever index was used. Lack of perfect correlation must therefore be a factor tending to reduce genetic progress below that expected from the simplest theory.

\section{Maternal effects}

Many geneticists have been preoccupied for several years with the effects of the size of the litter in which a gilt is reared on her subsequent reproductive performance. An effect was first noted by Falconer $(1955,1960)$ with mice and subsequently with pigs in the United States (see reviews by Robison, 1981; Rutledge, 1983). The fact that a dam transmits a half-sample of her genes to her daughters means that the regression of daughters' record on dam should estimate $\frac{1}{2} \mathrm{~h}^{2}$. However, the regression will be a biassed (downward) estimate of heritability to the extent that the daughter's record is depressed by the environmental effect of being reared in a litter of larger than average size.

The existence of such a negative environmental covariance is not in dispute. Evidence has come from selection and control lines, but also from intervention experiments in which cross-fostering has been used deliberately to rear pigs in small and large standardized litters. A negative phenotypic regression has often been found, suggesting that a gitt's litter size may be depressed on average by about 0.1 piglets for every one piglet increase in the size of the litter in which she was reared (van der Steen, 1983). The questions are (1) whether this effect is important as a factor to be exploited commercially, and (2) is this effect important as a complication lowering the efficiency of selection for litter size?

The first question cannot yet be answered clearly. There seems little scope for the deliberate rearing of replacement commercial (parent-level) gilts within artificially small litters. It would need to be at a cost which could be recouped by subsequent modest increments of improved performance, and these may not extend beyond the first parity. A more promising approach might be to understand the whole basis of the effect of pre- and post-natal environment on subsequent reproductive performance, to try to achieve the effects of the small fraternity size in some other way.

The second question, which is directly relevant to the effectiveness of genetic selection has been answered by van der Steen (1983). Indeed his answer is so clear that one must ask why so many others have been misled for so long?

The first issue is whether heritability estimated by daughter-dam regression (DD) really is lower 
than by alternative methods like grand-daughter : grand-dam regression (DG) or sib correlation, which avoid bias from maternal effects? Hill \& Webb (1982) concluded there were no consistent differences and newer work (Table 2) continues to support this. A possible reason may be that in large modern purebreeding herds, in contrast to the intervention experiments, a great deal of crossfostering to even out litter sizes near to the herd mean takes place. As a result large post-natal effects are avoided. Some small analyses (Revelle \& Robison, 1973; Vangen, 1980) did find much higher DG than DD estimates, although this might have been quite by chance, since they all had large standard errors.

However, the second issue is whether such a maternal bias, even if it existed, would cause "selection of gilts based on the litter size in which they were born (to) be ineffective in producing changes in the population average for litter size" (Robison, 1981). Van der Steen's (1983) insight came when he looked ahead to more than one generation of selection. It is true that the first few generations of selected gilts may have a performance lower than the starting point or the random mating control. This is because the environmental depression from being reared in large litters may more than cancel out the genetic lift from their superior dam's genes. However, the environmental bias is constant (or only very slowly growing as reared litter sizes increase) whereas the genetic increment accumulates in each generation. The net result should be that, after an initial depression (depending on the ratio of size of the negative maternal and positive genetic effects) the population responds at a rate proportional to the regression of a candidate's breeding value on dam's phenotypic value. This should only be $5-10 \%$ below the heritability calculated from the bias-free regression of daughter's record on dam's record. It should also be noted that most of the selection pressure will be through young males, chosen from the best dams, and these do not suffer the negative maternal effect.

Standardizing all litters at any constant value would be difficult in practice. Van der Steen (1983) investigated the effects of merely setting a minimum and maximum allowable size. He concluded that "even a small deviation from standardizing all litters ... results in a substantial reduction in the daughter-dam regression coefficient" since complete equalization of the numbers of piglets suckled by all sows is impossible. Hence advice to breeders to rear replacement gilts in standard litters seems unwarranted on genetic grounds.

In summary, these maternal effects are real, can have an effect on the interpretation of the early generation results in selection experiments but do not seriously reduce the rate of genetic improvement attainable in adequate experiments.

\section{Use of information from relatives}

Selection for litter size amongst young candidate boars and gilts suffers from several important handicaps. The trait can only be measured in one sex. It normally is first expressed only at about 1 year of age, and the heritability of a single record is low. These are just the conditions that favour selection of candidates on information provided by their adult, female relatives. The theoretica! basis for using such information was set out in a classic paper by Lush (1947), and this has been used by poultry breeders for many years. There has only recently been some interest in exploring specific applications of these methods to increasing litter size in pigs. Attention has mainly been focused on increasing accuracy of selection and hence rate of predicted response. This has been judged by $\rho$, the correlation between the selection criterion (an index combining several pieces of information) and the candidate's breeding value. When the candidate is evaluated on a single record of its dam (the base index), with an assumed heritability of $0 \cdot 1$ then $\rho=\frac{1}{2} h$ or $0 \cdot 16$.

Bereskin (1982) took as his base index a correlation of 0.25 (equivalent to a heritability of about 0.25 ). He then calculated that this correlation could be increased by over $70 \%$ (to 0.43 ) by using three records on the dam and single records on each of six paternal half-sibs (and hence a progeny test on the candidate's sire). Schinckel (1983) began with the base value of $0 \cdot 16$, and calculated that 
by including 3 records on the dam, 2 full-sibs (average of 2.5 records on each), 12 half-sibs of the dam $(2.5$ records), 3 records on the dam of the sire, 4 full-sibs of the sire $(2.5$ records) and 10 daughters (one record each), it could be increased by nearly $140 \%$ (to 0.38 ). Avalos \& Smith (1985) assumed a base index where the dam had two records $\left(\rho=0.21, h^{2}=0.10\right)$. By including the dam's full- (2) and half- (27) sibs, and the sire's full- (3) and half- (27) sibs, plus the sire's dam, each with two records, he catculated an increase of $74 \%$ in accuracy $(\rho=0.36)$.

In each of these studies the methodology is essentially the same. The results differ only because of the separate assumptions of the parameters, different base positions, and varied numbers and kinds of relatives providing information. Unfortunately, many years after Lush's paper (1947), they are all still only predictions. One reason, of course, why these ideas are being revived is that pig breeding organizations, public and private, now exist which both have adequate population sizes to utilize family selection techniques, and the knowledge and computing facilities to implement them. It remains to be seen if the theoretical advantages outweigh the considerable organizational problems and the tendency towards more rapid inbreeding.

\section{Effectiveness of selection for hyperprolific sows}

Legault \& Gruand's (1976) method for increasing litter size, through the exploitation of the small proportion of highly prolific sows found in any large population is now well known. Some of its features were discussed by Bichard \& Seidel (1983). It may be useful to consider the theory of the method in more detail in order to explore the situations in which a true net gain may be possible. This is a convenient way to emphasize the fact that litter size is not the only economic trait in pig production, and that it will only find a place in future selection schemes if the total return is higher than in existing schemes considering growth efficiency and carcass traits alone (hereafter called the growth traits).

In its simplest form (Fig. 1) a hyperprolific scheme could select for increased litter size among purebred females of one or more dam lines, in a series of cycles. Each cycle has two phases. In the first, prolific sows are identified, and produce sons, which may in turn be back-crossed one or more times to other prolific sows. This could take $\frac{1}{2}-2 \frac{1}{2}$ years or more. In the second phase, the new hyperprolific lines are expanded until they become the new dam lines at multiplier level and have the minimum number of records to allow the cycle to start.

During the expansion phase selection is only for growth traits, for perhaps 5 years. The ratio of the two phases determines how often selection for prolificacy can take place, e.g. $2 \frac{1}{2}: 5$ or the equivalent of $I$ year in 3 . Crosses between two such dam lines may be used as parent females. Parent boars would come from specialized sire lines selected in each generation solely for growth traits. It is assumed that the genetic correlations between the two sets of traits are zero. Hence the dam lines fall behind their potential in the growth traits only in so far as selection has not been applied to these in the first phase of each cycle.

The sustained annual rate of genetic change from selection on performance tests for the growth traits is $\Delta G_{1}$, worth $a_{1}$ per unit, or $A_{1}$ per year. In a sire line/dam line system one half of this is shown in the crossbred progeny, or $A_{1} / 2$ per year.

The genetic superiority of hyperprolific sows will be $R_{2}$ and is dependent on the accuracy of estimation of breeding value from repeated litter records, the proportion selected, and the variation in litter size. This full response can only be obtained after several generations of backcrossing. With only a single cross the gain should be $\frac{1}{2} R_{2}$, with one backcross before inter-se mating it should increase to $\frac{3}{4} R_{2}$ and so on: in general a fraction $R_{2}$.

The 'cost' of getting this response can be assessed in terms of the lag in growth traits $L_{1}$, which may be expressed as years of $\operatorname{lag}\left(D_{1}=L_{1} / \Delta G_{1}\right)$. The effective 'annual' rate of progress in litter size $\Delta G_{2}$ is therefore $f R_{2} / D_{1}$. If this is worth $a_{2}$ per unit the annual progress has a value of $a_{2} \Delta G_{2}$ or $\mathrm{A}_{\mathbf{2}}$. 


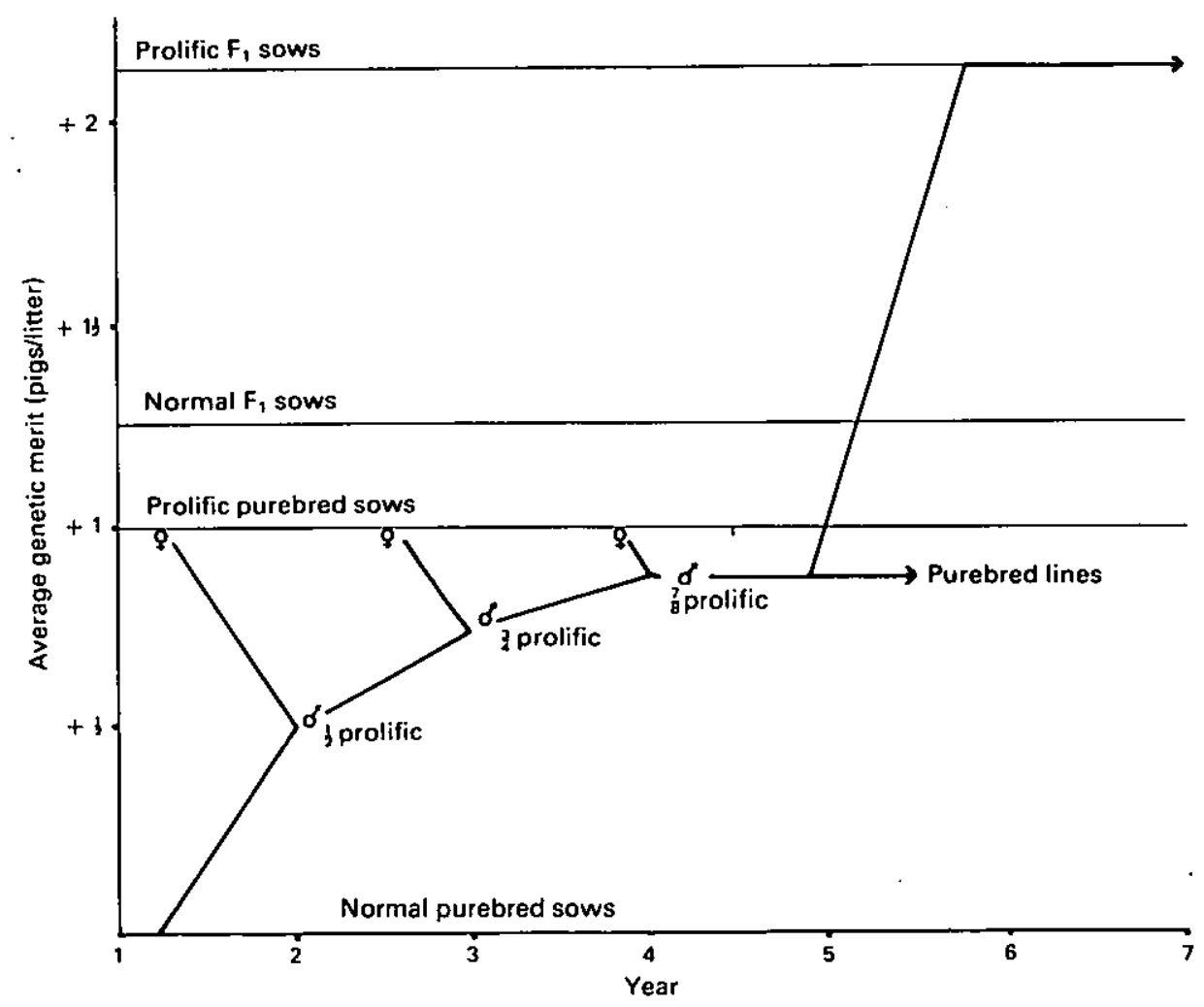

Fig. 1. Procedure for the exploitation of prolific sows (adapted from Legault \& Gruand, 1976).

The lag, $L_{1}$, is affected by:

(l) the age of selected prolific sows;

(2) the number of backcross generations;

(3) any selection which makes selected sows or boars better or worse than average for their generation in the growth traits;

as well as by $\Delta \mathrm{G}_{1}$.

Clearly if it is to be worthwhile relaxing growth selection for a period in each cycle of the dam lines, to select for litter size, then $A_{2}$ must equal or exceed $A_{1} / 2$.

\section{Methods of increasing $\Delta G_{2}$}

Since the effective 'annual' rate of genetic progress in litter size is a ratio of the genetic superiority of selected sows $\left(R_{2}\right)$ to the total lag incurred in the growth traits $\left(L_{1}\right)$, it may be maximized by increasing $R_{2}$ or decreasing $L_{1}$.

Increasing $R_{2}$. (1) Increase the selection differential

(a) by increasing the number of candidate sows

(i) using all possible purebred herds,

(ii) decreasing the minimum number of litters required before a sow is considered eligible for selection (though this will decrease accuracy) or

(b) by decreasing the number of sows selected (but this may increase inbreeding as the dam line passes through a bottleneck in each cycle). 
(2) Increase the accuracy of selection

(a) by increasing the minimum number of litters required for candidates (although this decreases the number of candidate sows) or

(b) by using information on the sow's relatives in addition to her own records.

(3) Gain additional selection pressure through choice of the first boars to mate to the prolific sows on the records of their female relatives (Skjervold, 1983, proposed progeny testing boars through artificial insemination).

Decreasing $L_{1}$. (4) Decrease the minimum age of eligible sows (but see laii and 2a above).

(5) Take fewer backcross generations (but the achieved fraction of $R_{2}$ will decrease).

(6) Select amongst candidate sows in part on their own performance in the growth traits.

(7) Select amongst sons of prolific sows during the backcrossing phase on their own performance in the growth traits.

\section{Simultaneous selection for prolificacy and growth traits}

It needs to be realized that, with current economic values for prolificacy and growth traits, the benefit obtained by including selection for prolificacy in a total improvement programme is often quite marginal. This is true whether the programme uses the hyperprolific approach outlined above, or a more conventional selection index system with continuous simultaneous selection for both groups of traits. Predictions of total net gain (economic efficiency of producing lean meat) are not increased dramatically over those considering only the growth traits which have been popular in Europe for the past 20 years (Smith, Dickerson, Tess \& Bennett, 1983; Avalos \& Smith, 1985). It is perhaps wise to be even more cautious about including reproduction with low weight in an overall index.

\section{The correct place for genetic selection}

This review is concerned with the effectiveness of selection. Even the best technique will be ineffective if it is applied in the wrong place. All pig herds exist somewhere within a pyramid of genetic improvement. An important feature is that genetic change created in the nucleus sector, at the small apex of the pyramid, is disseminated to the commercial or production herds in the numerically largest sector at the base. There may be one or more tiers of purebred or crossbred multiplication interposed between.

\section{Selection of gilt replacements at commercial level}

It is fundamental that only positive selection applied in the nucleus herds can have any cumulative effect, both within the nucleus and in the commercial tier below (Bichard, 1971). By contrast, positive selection applied in any other tier, multiplier or commercial, cannot succeed in creating genetic change beyond a certain limit. For example, in a herd which buys replacement boars but retains homebred gilts, selection of gilt replacements out of the best dams can only raise the herd mean by a maximal amount equal to the genetic superiority of the chosen dams. It will take 3 or 4 generations of selection to approach this maximum response. Once attained, selection must constantly be practised just to maintain this level. No more gains can accumulate since the boars bought in each generation cancel out further change. Johnson \& Ahlschwede (1982) summarized this by concluding that choosing a good boar supplier is much more important than selection of gilts within the commercial herd. 


\section{Culling at commercial level}

Negative selection (culling) within the commercial herd is almost totally ineffective in raising the mean performance level. The reasons are clear, though not yet widely appreciated.

(1) Any culling of sows before they die, become infertile or geriatric must result in an increased proportion of young females in the herd.

(2) Gilts, and to a lesser extent second-parity sows, are less productive than mature sows.

(3) Correlations between successive records of litter size (repeatability) are low $(r=0 \cdot 15)$.

(4) The increased performance of the survivors is not sufficient to offset the decreased productivity of the extra proportion of young sows, and hence give any significant gain in overal! herd output.

These conclusions were demonstrated by Strang \& King as long ago as 1970 but they continue to be ignored.

Selection for prolificacy will only be effective if it is based on sound techniques applied consistently within large populations over sufficient generations. This work will only benefit the commercial industry if effort is applied within the herds producing the primary breeding stock. Those advising the industry need to understand both of these concepts.

\section{References}

Avalos, E. \& Smith, C. (1985) Genetic improvement of litter size in pigs. A.F.R.C. Animal Breeding Research Organisation Report, 17-21.

Bereskin, B. (1982) Genetic evaluation of young boars and gilts for sow productivity. USDA Production Research Report 182, 1-29.

Bereskin, B. (1984) A genetic analysis of sow productivity traits. J. Anim. Sci. 59, I149-1163.

Bichard, M. (1971) Dissemination of genetic improvement through a livestock industry. Anim. Prod. 13, $410-4 ! 1$.

Bichard, M. \& Seidel, C.M. (1983) Selection for reproductive performance in maternal lines of pigs. Proc. 2nd World Congress on Genetics applied to Livestock Production 8, 565-569.

Bolet, G. \& Legault, C. (1982) Nuevas consideraciones sobre la mejora genética de la prolificidad en el cerdo. Proc. 2nd World Congress on Genetics applied to Livestock Production 5, 548-567.

Bolet, G., Tartar, M., Laloe, D. \& Felgines, C. (1984) Efficacité théorique de la sélection sur la prolificité chez le porc. Possibilitès de modifier l'indice actuel. Journées Rech. porcine en France 16, 475-480.

Cheng, P.L. (1983) A highly prolific pig breed of China - The Taihu pig. Pig News and Information 4, 407-425.

Falconer, D.S. (1955) Pattern of response in selection experiments with mice. Cold Spring Harb. Symp. quant. Biol. 20, 178-196.

Falconer, D.S. (1960) The genetics of litter size in mice. $J$. cell. comp. Physiol., Suppl. 1, 153-167.

Hill, W.G. \& Webb, A.J. (1982) Genetics of reproduction in the pig. In Control of Pig Reproduction, pp. 54l-564. Eds D. J. A. Cole \& G. R. Foxcroft. Butterworths, London.

Irvin, K.M. \& Swiger, J.A. (1984) Genetic and phenotypic parameters for sow productivity. J. Anim. Sci. 58, 1144-1150.

Johansson, K. (1981) Some notes concerning the genetic possibilities of improving sow fertility. Livest. Prod. Sci. 8, 431-447.

Johansson, K. \& Kennedy, B.W. (1982) Estimation of genetic parameters of fertility traits in pigs. Proc. 2nd World Congress on Genetics applied to Livestock Production 7, 503-508.

Johnson, R.K. \& Ahlschwede, W.T. (1982) Outcome of commercial cross-breeding strategies with selection for overall performance and litter size. Proc. Nat. Swine Improv. Fedn, Des Moines, pp. 56-63.

Johnson, R.K., Zimmerman, D.R. \& Kittok, R.J. (1984) Selection for components of reproduction in swine. Livest. Prod. Sci. 11, 54!-558.

Johnson, R.K., Zimmerman, D.R., Lamberson, W.R. \& Sasaki, S. (1985) Influencing prolificacy of sows by selection for physiological factors. J. Reprod. Fert., Suppl. 33, 139-149.

Legault, C. (1983) Breeding for large litters in swine. Proc. Illinois Pork Industry Conference, pp. 1-25.

Legault, C. (1985) Selection of breeds, strains and individual pigs for prolificacy. J. Reprod. Fert.. Suppl. 33, $151-166$.

Legault, C. \& Gruand, J. (1976) Amelioration de la prolificité des truies par la creation d'une lignée 'hyperprolifique' et l'usage de l'insemination artificielle: principe et résultats experimentaux préliminaires. Journées Rech. porcine en France 8, 201-206.

Lush, J.L. (1947) Family merit and individual merit as bases for selection. Am. Nat. 81, 241-261.

Ollivier, L. (1982) Selection for prolificacy in the pig. Pig New's and Information 3, 383-388.

Ollivier, L. \& Bolet, G. (1981) La sélection sur la prolificité chez la porc: résultats d'une expérience de sélection sur dix générations. Journées Rech. porcine en France 13, 261-268.

Revelle, T.J. \& Robison, O.W. (1973) An explanation for the low heritability of litter size in swine. J. Anim. Sci. 37, 668-678.

Robison, O.W. (1981) The influence of maternal effects 
on the efficiency of sclection; A review. Livestock Prod. Sci. 8, 121-137.

Rutledge, J.J. (1980) Fraternity size and swine reproduction. 1. Effect of fecundity of gilts. J. Anim. Sci. 51, 868-870.

Rutledge, J.J. (1983) Environmental effects of fraternal group size on reproductive efficiency. Proc. natn. Swine Improvement Fedn, Indianapolis 8, 9-14.

Schinckel, A. (1983) Estimated breeding values for swine improvement. Proc. natn. Swine Improvement Fedn. Indianapolis 8, 73-80.

Skjervold, H. (1983) A breeding scheme to improve prolificacy in pigs by intense sire and dam selection. Pig News and information 4, 427-430.

Smith, C. (1984) Rates of genetic improvement in farm livestock. Research and Devel. in Agric. 1, 79-85.

Smith, C., Dickerson, G.E., Tess, M.W. \& Bennett, G.L. (1983) Expected relative responses to selection for alternative measures of life cycle economic efficiency of pork production. J. Anim. Sci. 56, 1306-1314.

Strang, G.S. \& King, J.W.B. (1970) Litter productivity in Large White pigs. 2. Heritability and repeatability estimates. Anim. Prod. 12, 235-243.

Tartar, M. \& Bolet, G. (1984) Application de la théorie des indices de sélection à des caractères répétẻs. Example de la sélection sur la prolificité chez le porc. Genet. Sèl. Evol. 16, 319-334.

Tomes, G.J. \& Nielsen, H.E. (1984) Some aspects of selection for increased reproductive performance in sow herds. Proc. 8th Int. Pig Vet. Soc. Congress, Ghent, 203, Abstr.

van der Steen, H.A.M. (1983) Maternal and genetic influences on production and reproduction traits in pigs. Doctoral thesis, Wageningen.

Vangen, O. (1980) Studies on a two trait selection experiment in pigs. VI. Heritability estimates of reproductive traits. Influence of maternal effects. Acta agric. scand. 30, 320-326.

Vangen, O. (1981) Problems and possibilities for selection for fecundity in multiparous species. Pig News and Information 2, 257-263.

Vidovic, V. (1982) Estimation of genetic parameters for reproductive performance in purebred and crossbred sows. Proc. 2nd World Congress on Genetics applied to Livesiock Production 7, 288-292.

Young, L.D., Omtvedt, I.T., Whatley, J.A. \& Johnson, R.K. (1983a) Reciprocal recurrent selection for 21-day litter weight of crossbred gilts. I. Selection applied and genetic change in reproduction of crossbred gilts. J. Anim. Sci. 57, 1418-1430.

Young, L.D., Omtredt, I.T., Whatley, J.A. \& Johnson, R.K. (1983b) Reciprocal recurrent selection for 21day litter weight of crossbred gilts. II. Reproductive performance of purebred females producing purebred and two-way cross litters and performance of purebred and crossbred pigs. J. Anim. Sci. 57, 1431-1439. 